\title{
Beyond individual responsibility for lifestyle: granting a fresh and fair start to the regretful
}

Sarah Vansteenkiste

Kurt Devooght

Erik Schokkaert
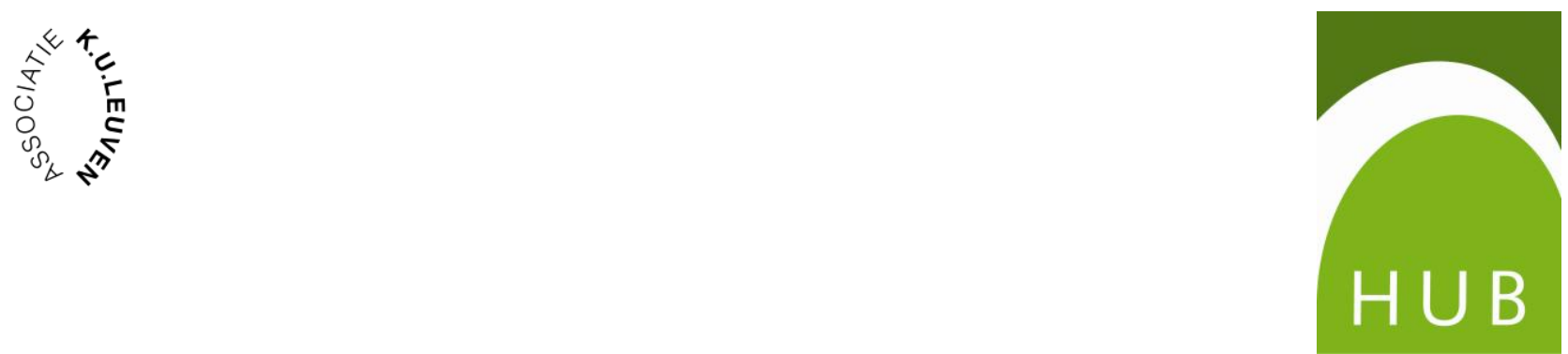


\title{
Beyond individual responsibility for lifestyle: granting a fresh and fair start to the regretful
}

\begin{abstract}
As lifestyle diseases put a heavy burden on health care expenditures, voices are raised and win in sound to hold people responsible for their unhealthy lifestyle. Most of the arguments in favour of responsibility are backward-looking. In this paper, we describe the distributional consequences of these backward-looking measures and show that they are very harsh on those who regret a past unhealthy lifestyle. We demonstrate that it is possible to take policy measures which respect individual responsibility but which are at the same time able to grant fresh starts to individuals who regret their past unhealthy lifestyle (which is an application of Fleurbaey (2005)). This "forgiving" policy is confronted with a moral hazard problem, however. In general the regulator does not observe whether individuals really regret their past choices or if they just pretend to have changed preferences in order to enjoy the compensatory measures for regretful people. In this paper, we argue that the health setting offers interesting opportunities to move beyond this moral hazard problem and offer a solution through the use of redistributive instruments that are conditional on lifestyle changes.
\end{abstract}

Keywords: equivalent resources, freedom, fresh start, luck egalitarianism, regret, responsibility, responsibility-sensitive egalitarianism, unhealthy lifestyle

\author{
Sarah Vansteenkiste ${ }^{1}$, Kurt Devooght ${ }^{2}$, Erik Schokkaert ${ }^{3}$ \\ ${ }^{I}$ Department of Business Economics, University of Leuven \\ ${ }^{2}$ CEDON HUBrussel and Centre for Economics and Ethics, University of Leuven \\ ${ }^{3}$ Department of Economics, University of Leuven
}

Correspondence should be addressed to: Sarah Vansteenkiste, Naamsestraat 69, 3000 Leuven, Belgium. Email: sarah.vansteenkiste@kuleuven.be. Telephone number: +32 1632 3055. 


\section{Beyond individual responsibility for lifestyle: granting a fresh and fair start to the regretful}

\section{Introduction: responsibility, rights and freedom}

Lifestyle diseases are becoming one of the major determinants of total health care costs (Finkelstein et al. 2003 and 2004; Visscher \& Seidell, 2001). Being obese, for instance, is associated with an increased mortality, an increased number of annual hospital days and an increased chance of contracting a severe disease, like cancer, cardiovascular disease, diabetes, coronary heart disease, gallbladder disease, osteoarthritis and asthma (Allison et al., 1999; Flegal et al., 2005; Fontaine et al., 2003; Kannel, 1997; McPherson et al., 2007; Mokdad et al., 2004; Quesenberry et al. 1998; Visscher \& Seidell, 2001; WCRFA, 1997). Since lifestyle diseases are (partly) self-inflicted, voices are raised to hold people responsible for their unhealthy lifestyle, e.g. by levying taxes on their behaviour, letting them pay higher health care contributions, giving them lower priority to certain treatments or denying them treatments altogether. These proposals have led to a heated debate (Buyx, 2008; Cappelen \& Norheim, 2005 and 2006; Feiring, 2008; Le Grand, 1991; Morreim, 2000; Schmidt, 2007; Underwood \& Bailey, 1993). Opponents point out that individuals are not always fully rational and may base their decisions on incomplete information, that they may be tempted to go for immediate gratification rather than considering long-run consequences - and, more importantly, that this behaviour is explained by psychological (even genetically determined) mechanisms for which individuals cannot be held responsible. Moreover, the existence of a social gradient suggests that the social environment also has a strong influence on lifestyle and that a responsibility policy therefore would lead to increasing social inequality.

The different positions in this debate can be related to deeper underlying philosophical differences. Overly simplified, one could say that there are two different sets of 
arguments to sustain the idea of responsibility. The first is related to the traditional libertarian position holding that justice does not require the global health insurance system to go beyond enlightened self-interest and to care for the weaker or sicker individuals in society. In such an individualistic (or pure insurance) perspective, responsibility for own behaviour is selfevident. A weaker variant of this position accepts the idea of some redistribution through health insurance, but points to the additional costs that are imposed by individuals with unhealthy lifestyles on other individuals. Economists talk in this context about externalities. The idea is that everybody does have the right to pick his own lifestyle, but has to compensate others if this lifestyle imposes costs on them. These positions are not really new. Moreover, it is not surprising that their support is growing in a context of rapidly and sharply increasing health care expenditures. What is more surprising from an intellectual point of view is that in recent years the idea of responsibility has also been defended by egalitarian thinkers. They offer a second set of arguments to hold people responsible for their unhealthy lifestyle. Philosophers have coined the term "luck egalitarianism" - economists, who associate luck with random variation, prefer the term "responsibility-sensitive egalitarianism" (henceforth RSE), but the ideas are similar. RSE theory holds that a good society should equalize well-being for individuals that have exerted the same degree of responsibility. This is its egalitarian component. However, if the differences in life situations reflect differences in factors for which individuals are to be held responsible, redistribution is undesirable. As an application, disparities in health between two individuals are inequitable when they reflect factors for which individuals are not responsible, whereas these disparities are equitable if they are due to factors for which individuals are held responsible. ${ }^{1}$ This second, egalitarian, justification for responsibility-sensitivity is the more challenging one from an intellectual point of view, and we will explore in this paper some of its implications. We will come back to the externalities argument in the last section. 
The description of RSE in the previous paragraph has remained rather abstract, because we did not specify for which factors individuals are to be held responsible. Broadly speaking, two different answers to this question have been formulated in the literature. The first is close to the original inspiration of responsibility-sensitive egalitarianism, as found in Rawls (1971) and Dworkin (1981a and b, 2000). This approach starts from the idea that people have different objectives in life and should get the (real) freedom to pursue their own objectives. But this real freedom at the same time implies responsibility. ${ }^{2}$ Respect for human dignity and for individual freedom includes naturally respect for the consequences of one's choices. A second approach (Cohen, 1989; Arneson, 1989; Roemer, 1998) rejects this responsibility for "preferences" on the basis that sometimes individuals do not "choose" their own preferences, in so far as these are formed by the individual's genetic and social background. These authors argue that individuals should only be held responsible for things that are under their control, that they themselves have chosen. Yet once choices have been made, individuals have to bear the consequences of their choices. This second approach has rapidly gained popularity, perhaps because it reflects better the common-sense view on responsibility. It seems also to dominate the debate concerning responsibility in health care. Proponents of the first approach have replied that this "control"-view brings us on a slippery quasi-metaphysical slope once we have to define what is control and freedom in a largely deterministic view of the world (Fleurbaey, 2008). In this paper, we will not go into the various philosophical arguments that have been raised in the debate between these two views. ${ }^{3}$ We will focus on the first (preference or freedom) approach and explore its potential answer to a prominent point of criticism against introducing responsibility considerations in the financing of health care policy.

Critics have pointed out that RSE is essentially backward-looking (a term which is also used by Feiring, 2008). This is indeed true for the "control"-approach, in which the 
optimal redistribution of social resources is merely based on the resources persons initially received and on the choices they made regarding these resources. Hence, according to this theory only one's past choices are of interest and not the current visions on life one holds. This can have harsh consequences, especially in a health setting. Ascribing responsibility for past choices means that people whose poor health follows from their past choices have no right to be helped - this leads to proposals which give these people lower priority to certain treatments. The fact that individuals regret their past decisions is not relevant in this approach. They should have known better before. This is especially worrying because health has such an important impact on the future opportunities of people.

While all this is true for the "control"-approach, the "preference"-approach opens a possibility to be more lenient. It can take into account that individuals who adopted an unhealthy lifestyle may become regretful and may want to change their behaviour in a healthier direction. It is not necessarily backward looking if it puts an individual's current mind-set central rather than his or her past mind-set. This allows compassion for these people who feel regret for past decisions after they have consciously and genuinely changed preferences. As has been argued by Fleurbaey (2005, 2008), these people can get a "fresh start". What is more, they should get a fresh start, because disregarding regret is freedomreducing. Choices made in the past can encumber future prospects in such a way that the real freedom to pursue one's (new) genuine objectives in life is heavily reduced. Ex ante, this is a limitation of the freedom for everybody, because it becomes difficult for everybody to change preferences. In this paper, we will apply these ideas to the issue of responsibility for lifestyles in a health setting.

Note that we assume that the preferences used for evaluating individual situations are genuine and well-informed. Of course, it is not always easy to identify these informed preferences - and they are definitely not always revealed in actual behaviour. Actual Body 
Mass Index (BMI) for instance, increases faster than desired BMI, demonstrating that a lot of obese individuals would prefer to weigh less (Cutler et al. 2003). Yet, this is not an essential point in our argumentation, since it does not distinguish the "preference" and the "control" approach. While the former respects genuine and well-informed preferences as a matter of principle, the latter may also argue that "alienated" preferences are a typical example of preferences that are not controlled. In both cases individuals should therefore not be held responsible for choices based on them. The more challenging questions arise when we focus on genuine preference changes. ${ }^{4}$

In section 2 we describe the distributional consequences of backward-looking measures that aim at including responsibility for one's lifestyle. Section 3 (basically an application of Fleurbaey, 2005) demonstrates that it is possible to take policy measures which respect individual responsibility but which are at the same time able to grant fresh starts to individuals who regret their past unhealthy lifestyle. In section 4 we argue that the health setting offers interesting opportunities to improve upon Fleurbaey's solution through the use of redistributive instruments (e.g. health cheques) that are conditional on lifestyle changes. Finally, in section 5, we come back to the libertarian (or externalities) position and shows how it relates to the idea of a fresh start. Section 6 concludes.

\section{Distributional consequences of regret in RSE theories}

We introduce a simple illustrative example to clarify the distributional differences between looking at people's current or past mind-set (see Table 1). This simple example will be used throughout this paper. ${ }^{5}$ Assume that individuals only live for two periods. Each individual gets the same initial resources of 300 to start his or her life with. In each period, individuals can divide half of their resources on a festive activity (e.g. eating lots of twinkies) and on a healthy activity (e.g. eating fruit and vegetables). Assume that one can only be 
healthy by spending resources on the healthy activity and that this is a one-on-one relationship. That is, spending 100 on the healthy activity gives rise to a health outcome of 100. A perfect health can be obtained by spending 300 on the healthy activity, whereas spending all resources on the festive activity leads to the worst possible health-status, which implies having a bad health, but not so that people would decease. In period 1 the population consists of two groups of equal size. The first group consists of individuals who care for their health and spend each period half of their resources on the healthy activity. We call them the prudent-foodies because they eat healthy so that in the end they do not damage their health. The second group contains the individuals who are only interested in the festive activity. We call them the junk-foodies because they like spending all of their resources on junk food (i.e. the festive activity) in each of the two periods and therefore cause harm to their health. In period 2, the prudent-foodies have no regrets about past decisions, while half of the junkfoodies do have regrets about their past unhealthy lifestyle and would like to have lived as a prudent-foodie. These regretful junk-foodies can however not restore their past choices. The only thing they can do is spending the remaining part of their resources on the healthy activity in period 2. As such, in period 2, the population can be divided into three groups: (i) the prudent-foodies (50\%), (ii) the regretful junk-foodies (25\%) and (iii) the non-regretful junk-foodies $(25 \%)$.

Let us now first evaluate the situation from the control-perspective, in which only the persons' initial resources and the decisions they made in the past matter. Since everyone got the same amount of initial resources of 300 , there is no need to have redistributional measures between the three population groups. The differences in health outcomes that can be observed are due to the different choices people made during their life. People who regret their outcome at the end of period 1 , do not have a leg to stand on. 
The forgiving approach leads to a very different conclusion. If we evaluate the position of the regretful junk-foodies from their current mind-set, then obviously their initial resources are no longer adequate as a description of their situation. Fleurbaey $(2005,2008)$ proposes to evaluate the well-being of individuals in terms of their so-called equivalent resources: "A good measure of individual situations cannot be the share of initial resources [...] A more relevant measure [...] is the share of resources which would have given people, with their current preferences, a situation which they consider equivalent to their current situation. When someone says 'My current situation is as good as if I had applied my current preferences to a share of resources equal to $X^{\prime}$, the value of $X$, which may differ across individuals, is the proposed measure of this individual's situation" (Fleurbaey, 2005, p. 42). ${ }^{6}$ In our example, this implies assessing the current situation of a regretful junk-foodie through the eyes of a prudent-foodie, since a regretful junk-foodie now thinks like a prudent-foodie and has the same life goals. A prudent-foodie who is confronted with the outcome of a regretful junk-foodie at the beginning of period 2, would have liked to spend less on the festive activity and have more left to spend on the healthy activity. A prudent-foodie evaluates the expenditures of 150 on the festive activity only as 0 , since a prudent-foodie would spend nothing on the festive activity. Expenditures on the festive activity do not warrant him any satisfaction. Through the eyes of a prudent-foodie therefore, having spent 150 on the festive activity and having only 150 left to spend on the healthy activity results in equivalent resources of 150 (i.e. $0+150$ ). Hence, for the regretful junk-foodies, the equivalent resources are strictly smaller than the initial resources they received (150 compared to 300), whereas for non-regretful junk-foodies and prudent-foodies, the equivalent resources are just their actual resources.

As is noticeable from Table 1, the situation set out in the above example leads to an imbalanced distribution in terms of equivalent resources. The regretful junk-foodies are worst 
off. The prudent foodies and, more strikingly, the non-regretful junk foodies are both better off, since they do not regret their past decisions. In a "freedom"-perspective, this situation is not optimal. We will now show how different instruments can be used to rectify this situation.

Table 1. Distribution of the initial and equivalent resources

\begin{tabular}{l|ccc} 
& $\begin{array}{c}\text { prudent- } \\
\text { foodies }\end{array}$ & $\begin{array}{c}\text { regretful junk- } \\
\text { foodies }\end{array}$ & $\begin{array}{c}\text { non-regretful } \\
\text { junk-foodies }\end{array}$ \\
\hline \hline Period 1 & & & \\
• Expenditures on healthy activities & 150 & 0 & 0 \\
• Expenditures on festive activities & 0 & 150 & 150 \\
\hline Period & & & 0 \\
- Expenditures on healthy activities & 150 & 150 & 150 \\
• Expenditures on festive activities & 0 & 0 & 300 \\
\hline \hline Initial resources & 300 & 300 & 300 \\
Equivalent resources & 300 & 150 & 0 \\
Health outcome & 300 & 150 &
\end{tabular}

\section{Redistributing equivalent resources in a second-best setting: the Fleurbaey} solution

Rectifying the situation in Table 1 may seem easy at first sight - simply transfer part of the resources from the prudent-foodies and the non-regretful junk foodies to the regretful junk-foodies. ${ }^{7}$ But this is a naive approach, since the regulator (or the redistributive agency, or the collective health insurance system) does not observe for individual junk-foodies whether they really regret their past choices or not. ${ }^{8}$ It can distinguish prudent-foodies from junk foodies based on observed behaviour in period 1, but to distinguish regretful from nonregretful junk-foodies it needs information which only the junk-foodies themselves possess and control. The knowledge that reporting oneself as a non-regretful costs resources whereas outing oneself as a regretful yields additional resources, will tempt the non-regretful to report themselves as regretful thus making the whole exercise pointless. In other words, any 
proposed policy measure should be moral hazard-proof. This moves us into what economists call a "second-best" setting.

Fleurbaey $(2005,2008)$ shows that a policy designed to improve the inequitable situation in which regretful junk-foodies find themselves consists of two components. Firstly, the government should impose a 'help' egalitarian intervention, which aims at improving the equivalent resources of the worst off (i.e. the regretful junk-foodies) by letting the prudentfoodies pay a tax which is then reimbursed to (all) junk-foodies. Assume for example that the prudent-foodies have to pay a tax of 50 in period 1 (see Table 2). Both the regretful and the non-regretful junk foodies get 50 which they will spend in period 2 on healthy and festive activities respectively. The end result would be a situation where the non-regretful junk foodies are better off in terms of equivalent resources than the prudent-foodies (and a fortiori than the regretful junk foodies).

Therefore, the optimal second best-policy has to include a second component. On top of the 'help' intervention, there should also be a protective intervention. This regulatory measure imposes that every individual should pay a minimum amount of attention to his health by spending at least some resources on the healthy activity. In table 2 we show the effect of such a protective interference: every individual has to spend a minimum of 50 on his health. For the prudent-foodies this additional constraint is not binding: they already spend voluntarily more than 50 on health. Junk-foodies, however, who only care about the festive activity, are forced to spend the bare minimum of 50 on the healthy activity in period 1 . This measure imposes an overall cost on the non-regretful junk foodies, as they do not care about their health in period 2 either. However, it lowers the cost of improving the situation for the regretful junk-foodies, since at the start of period 2, they are glad that this minimum of healthy activities was imposed on them in period 1 . This measure therefore aims at protecting 
people from potential future regret. It lowers the cost of the overall policy for the prudentfoodies, since part of the redistributive burden is now borne by the non-regretful junk foodies.

How do both interventions affect the equivalent endowments of each population group? Let us first look at the prudent-foodies. They feel no effect of the protective measure. However, due to the tax they have to pay their equivalent endowments are smaller than before and equal 250. What about the junk-foodies? Firstly, even though the non-regretful junk-foodies obtain a subsidy of 50 in period 2, they have a reduced amount of equivalent resources since they are obliged to take on a healthier lifestyle which goes against their preferences. Their equivalent resources now amount to 250 . The regretful junk-foodies on the other hand, gain from both the help and the protective intervention. As a consequence, their equivalent endowments increase significantly in comparison with the previous scenario without interventions. They now have the same amount of equivalent endowments (250) as the prudent-foodies and the non-regretful junk-foodies. Hence, imposing both policy measures results in a balanced distribution between the prudent- and junk-foodies in terms of equivalent resources.

While we reach equality of equivalent resources at the end, it may seem counterintuitive that the non-regretful junk-foodies also benefit from a subsidy for an unhealthy lifestyle which they do not wish to adapt. Moreover, the protective intervention introduces waste in the system, since the non-regretful junk foodies have to spend resources on the healthy activity which is not valuable to them. Both problems are unavoidable if the regulator cannot distinguish the regretful from the non-regretful junk-foodies. Things change, however, if he has an instrument at his disposal which makes it possible to treat the regretful and the non-regretful differently. We now turn to this possibility. 
Table 2. Distribution of the equivalent resources in a second-best setting

\begin{tabular}{l|ccc} 
& $\begin{array}{c}\text { prudent- } \\
\text { foodies }\end{array}$ & $\begin{array}{c}\text { regretful junk- } \\
\text { foodies }\end{array}$ & $\begin{array}{c}\text { non-regretful } \\
\text { junk-foodies }\end{array}$ \\
\hline \hline $\begin{array}{l}\text { Period 1 } \\
\text { - Expenditures on healthy activities }\end{array}$ & 100 & 50 & 50 \\
- Expenditures on festive activities & 0 & 100 & 100 \\
• Tax & 50 & $/$ & $/$ \\
\hline $\begin{array}{l}\text { Period 2 } \\
\text { - Expenditures on healthy activities }\end{array}$ & 150 & $150+50$ & 50 \\
$\quad$ Expenditures on festive activities & 0 & 0 & $100+50$ \\
\hline \hline Equivalent resources & 250 & 250 & 250 \\
Health outcome & 250 & 250 & 100
\end{tabular}

\section{Distinguishing the regretful from the non-regretful by using a health cheque}

In a health care context instruments are available that make it possible to redistribute only to those junk-foodies who are really regretful, i.e. who really change their preferences. The most natural example in our setting is the emission of health cheques funded by the collection of health taxes. These health cheques are issued by name and offered for free to smokers, obese persons, and other groups which society considers as leading an unhealthy lifestyle. Health cheques can only be exchanged for a personal health programme: diet programs, access to the gym or sports programs, anti-addiction programs, psychological help, professional advice, etc. One could additionally impose that the cheques are only fully reimbursed after the program has been completed. The crucial feature of this policy instrument is that it induces a sort of (truthful) self-identification by the regretful. Health cheques are different from unconditional cash transfers in that they can only be used to invest in health care programs which are approved by the government. Since the non-regretful junk foodies do not want to invest in healthy activities, they will simply not use their health cheques. Half of the cheques that are issued will then not entail any real cost, and the whole tax revenue can ultimately go to the regretful junk-foodies. 
It is important to notice that this proposition can lead to a larger amount of equivalent resources for every population group. In fact, the use of an instrument that (implicitly) differentiates between the regretful and the non-regretful junk foodies makes the "protective" component in the second best-policy unnecessary - and therefore avoids the waste that is induced by it. We can briefly illustrate this by returning to our previous example. An egalitarian solution where both the regretful and non-regretful junk-foodies as well as the prudent-foodies have the same amount of equivalent resources, can be obtained by letting everybody pay a tax of 30 in the first period. The collected taxes are now used to finance a system of health cheques that can be issued for the junk-foodies at the start of period 2 . Because the non-regretful junk-foodies will not use the health cheque, the amount that can be emitted on every cheque equals 120 . As the regretful junk-foodies are now able to spend the same amounts on the healthy activity as the prudent-foodies, their equivalent endowments are equivalent to those of the latter and amount to 270 . This is also equal to the amount of equivalent resources of the non-regretful junk-foodies. Hence, thanks to the health cheque that makes it possible to distinguish the regretful from the non-regretful, the total amount of the equivalent resources of every population group is higher than in the previous scenario (270 compared to 250$)$.

This system is not paternalistic, in that it does not impose on all junk-foodies a change in their lifestyle. It does entail, however, that individuals with past unhealthy lifestyles are given the opportunity to regain their health. More precisely, they get the opportunities to invest more in their own health in order to overcome the consequences of their past behaviour. Moreover, people may choose their own health project, which can increase their chances of regaining a better health status. This proposal is similar to, but slightly different from the one that is put forward by Feiring (2008). He makes health care for the junk-foodies conditional on their changing their lifestyle, with as main argument that this would improve 
treatment efficacy. This argument is not needed in the preference-based fresh start approach, which offers all junk-foodies the opportunity to change their behaviour and takes it for granted that "competent and well-informed individuals are the best interpreters of their own interest" (Feiring, 2008, p. 36).

Table 3. The effect of introducing conditional redistributive instruments

\begin{tabular}{l|ccc} 
& $\begin{array}{c}\text { prudent- } \\
\text { foodies }\end{array}$ & $\begin{array}{c}\text { regretful junk- } \\
\text { foodies }\end{array}$ & $\begin{array}{c}\text { non-regretful } \\
\text { junk-foodies }\end{array}$ \\
\hline \hline Period 1 & & & \\
- Expenditures on healthy activities & 120 & 120 & 0 \\
- Expenditures on festive activities & 0 & 30 & 120 \\
- Tax & 30 & & 30 \\
\hline Period 2 & 150 & $150+120$ & 0 \\
- Expenditures on healthy activities & 0 & 0 & 150 \\
\hline$\quad$ Expenditures on festive activities & 270 & 270 & 270 \\
\hline \hline Equivalent resources & 270 & 270 & 0
\end{tabular}

\section{Funding the health cheque system by the junk-foodies}

Up to now we have presented two scenario's which ultimately resulted in an equal distribution of the equivalent endowments. Both of these scenario's fitted the interpretation of 'responsibility as real freedom' and implied that no moralizing stance is taken with respect to what is the "better" lifestyle. However, as mentioned in the introduction, other advocates of introducing responsibility considerations in health care allocation, might argue that there is no reason why the prudent-foodies would have to pay for those who - in their eyes - behaved improperly. On the contrary, it should be those who act 'irresponsibly' towards their health who have to pay the health tax. If we want to offer a new start to the regretful junk-foodies, only the junk-foodies should bear the resulting burden.

Let us have a closer look at what this implies for the distribution of the equivalent resources of both the prudent- and junk-foodies. We are "forgiving" and therefore we still 
aim at a situation where the equivalent endowments are equal between the prudent-foodies and the regretful junk-foodies. Such a distribution can for instance be reached by letting those who spend part of their resources on the festive activity pay a health tax of 75 at the end of period 1, which is reimbursed as a health cheque of 150 in period 2. In that case, the regretful junk-foodies are now able to spend the same amount of resources on the healthy activity as the prudent-foodies, so that their equivalent endowments amount to the same total of 300 (table 4). The non-regretful junk-foodies on the other hand, have only equivalent resources of 225 left, since they now fully pay for the fresh start of the regretful junk-foodies.

It is worth pointing to the differences between the results in Tables 3 and 4 . The imposition of a tax on junk-foodies is very harsh on the non-regretful junk-foodies. Not only do they bear the consequences of their choices in terms of poor health - something which may be seen as unproblematic for any RSE, but in addition they reach a lower welfare level in the light of their own personal preferences, i.e. they have a smaller amount of equivalent resources. This end result can only be justified in a paternalistic view of the world, in which the healthy lifestyle is seen as morally superior. Such a disciplining approach does not fit into the real-freedom approach that we explored in this paper. ${ }^{9}$

Table 4. Effects of a tax on the junk-foodies

\begin{tabular}{l|ccc} 
& $\begin{array}{c}\text { prudent- } \\
\text { foodies }\end{array}$ & $\begin{array}{c}\text { regretful junk- } \\
\text { foodies }\end{array}$ & $\begin{array}{c}\text { non-regretful junk- } \\
\text { foodies }\end{array}$ \\
\hline \hline Period 1 & & & \\
• Expenditures on healthy activities & 150 & 0 & 75 \\
- Expenditures on festive activities & 0 & 75 & 75 \\
\hline$\quad$ Health tax & $/$ & & 0 \\
\hline Period 2 & & $150+150$ & 150 \\
• Expenditures on healthy activities & 150 & 0 & 225 \\
• Expenditures on festive activities & 0 & 300 & 0
\end{tabular}




\section{Conclusion}

Introducing responsibility considerations in a health care context in a backwardlooking way, can be very harsh on those who have chosen an unhealthy lifestyle in the past. On the other hand, individuals may have different ideas about what is really important in life - and responsibility is the necessary counterpart of freedom. Therefore respect for the autonomy of individuals implies at the same time that it should not be seen as problematic that individuals who deliberately opted for an unhealthy lifestyle end up at a lower health level.

Yet, real freedom also implies the freedom to change preferences. A good society should therefore offer to everybody the possibility to take a fresh start. One way to implement this idea is to accept that the opportunities of different individuals should be evaluated on the basis of their current (and not their past) ideas about what is a good life. Individuals who changed ideas should then be compensated for past mistakes.

A "forgiving" policy is confronted with a moral hazard problem, however. In general it is not possible for the regulator to distinguish between those who really changed their genuine preferences and those who claim the compensatory transfer by pretending to have changed preferences. Therefore an optimal forgiveness policy will include some regulatory ("protective") measures that impose on everybody a minimally healthy behaviour. The only way to circumvent this problem is to use a policy instrument which gives individuals the incentives to self-select. Conditional transfers, such as health cheques, may have this beneficial feature, and should therefore be used extensively. While we pointed out that the use of such conditional transfers may in principle make regulation of lifestyles unnecessary, in actual reality their effectiveness to restore the welfare level of the regretful may be relatively small. It is therefore worth emphasizing that a mixed policy is also possible, i.e. a combination of conditional transfers with "protective" measures imposing a minimally 
healthy lifestyle on everybody. Note the paradox: restrictive measures such as fat taxes and smoking prohibitions can be defended from the point of view of real freedom, even if we neglect fully the argument of externalities.

The approach described in this paper is not moralizing, in that it does not start from an apriori idea about the ethical superiority of one or other lifestyle. It is not backward-looking or disciplining either, in that it fully respects the freedom of individuals and ultimately results in an equal distribution of equivalent resources. It is reassuring that a policy guaranteeing real freedom to everyone ultimately results in a realistic set of policy instruments (some health behaviour regulation, conditional transfers) that may be acceptable to a large fraction of the population.

\section{Notes}

${ }^{1}$ It has been shown that the two principles cannot be satisfied simultaneously if they interact in explaining behaviour so that the relative contributions of the different factors in the explanation of behaviour cannot easily be distinguished. Compromise solutions are then needed. We will not discuss this issue in this paper - see Fleurbaey and Schokkaert $(2009,2012)$ for an overview of the formal literature on responsibility-sensitive egalitarianism in health.

2 "Responsibility requires freedom.... Without the substantive freedom and capability to do something, a person cannot be responsible for doing it. But actually having the freedom and capability to do something does impose on the person the duty to consider whether to do it or not, this does involve individual responsibility. In this sense, freedom is both necessary and sufficient for responsibility" (Sen, 1999).

${ }^{3}$ There is also some empirical work on the opinions of lay respondents about where to draw the responsibility cut. Both the "preference" and the "control" approach are supported by respondents in Belgium, Burkina Faso and Indonesia (Schokkaert and Devooght, 2003).

${ }^{4}$ Fleurbaey draws attention to a paradox here. The "control"-approach would hold individuals responsible for their past choices if they deliberately change preferences (because then preferences are under control), while forgiveness would be granted if the change were not conscious, but happened e.g. because of a brain injury. 
Fleurbaey (2005, p.34) rightly wonders: "Does it make sense to say that an individual who is responsible for a decision stops being tied to its consequences when he is not responsible for a later change of mind, whereas a thoroughly managed change of mind yielding the same regret does not have the same effect?"

${ }^{5}$ A rigorous mathematical analysis in the context of savings decisions can be found in Fleurbaey $(2005,2008)$.

${ }^{6}$ The basic ideas of forgiveness and fresh starts can be developed without using this concept of equivalent resources, but in our simple setting it is a very convenient concept. It plays an important role in all developments of the theory of fair allocation, which starts from the presumption that preferences should be respected but not individual subjective feelings of utility - see Fleurbaey (2008), Fleurbaey and Maniquet (2011), and for a survey in the context of health, Fleurbaey and Schokkaert (2012).

${ }^{7}$ Note that transferring resources only from the non-regretful junk foodies would imply that one evaluates their life project as less valuable than that of the prudent foodies. This "paternalistic" attitude goes against respect for individual preferences. We will come back to it in section 6 .

${ }^{8}$ We follow the traditional assumption that the regulator knows the proportion of regretful junk-foodies in the population but cannot distinguish for each individual separately if she is regretful or not.

${ }^{9}$ Ubel et al. (1999) present some fascinating empirical results, suggesting that the opinions of "responsibilitysensitive" citizens may be heavily influenced by such "disciplining” views on non-conventional lifestyles.

\section{References}

Allison, D.B., Fontaine, K.R., Manson, J.E., Stevens, J. and Vanitallie, T.B. 1999. Annual deaths attributable to obesity in the United States. Journal of the American Medical Association, 282(16), 1530-1538.

Arneson, R. 1989. Equality and equal opportunity for welfare. Philosophical Studies, 56, 7793.

Buyx, A.M. 2008. Personal responsibility for health as a rationing criterion: why we don't like it and why maybe we should. Journal of Medical Ethics, 34, 871-874. 
Cappelen, A.W. and Norheim, O.F. 2005. Responsibility in health care: a liberal egalitarian approach. Journal of Medical Ethics, 31, 476-480.

Cappelen, A.W. and Norheim, O.F. 2006. Responsibility, fairness and rationing in health care. Health Policy, 76(3), 312-319.

Cohen, G. 1989. On the currency of egalitarian justice. Ethics, 99, 906-944.

Cutler, D., Glaeser, E. and Shapiro, J. 2003. Why have Americans become more obese? Journal of Economic Perspectives, 17, 93-118.

Dworkin, R. 1981a. What is equality? Part 1: Equality of welfare. Philosophy and Public Affairs, 10, 185-246.

Dworkin, R. 1981b. What is equality? Part 2: Equality of resources. Philosophy and Public Affairs, 10, 283-345.

Dworkin, R. 2000. Sovereign virtue. Cambridge: Cambridge University Press.

Feiring, E. 2008. Lifestyle, responsibility and justice. Journal of Medical Ethics, 34(1), 3336.

Finkelstein, E.A., Fiebelkorn, I.C. and Wang, G. 2003. National medical spending attributable to overweight and obesity: how much, and who's paying? Health Affairs, W3219-226.

Finkelstein, E.A., Fiebelkorn, I.C. and Wang, G. 2004. State-level estimates of annual medical expenditures attributable to obesity. Obesity Research, 12(1), 18-24.

Flegal, K.M., Graubard, B.I., Williamson, D.F. and Gail, M.H. 2005. Excess deaths associated with underweight, overweight, and obesity. Journal of the American Medical Association, 293(15), 1861-1867. 
Fleurbaey, M. 2005. Freedom with forgiveness. Politics, philosophy \& economics, 4(1), 2967.

Fleurbaey, M. 2008. Fairness, responsibility and welfare. New York: Oxford University Press.

Fleurbaey, M. and Maniquet, F. 2011. A theory of fairness and social welfare. Cambridge: Cambridge University Press.

Fleurbaey, M. and Schokkaert, E. 2009. Unfair inequalities in health and health care. Journal of Health Economics, 28, 73-90.

Fleurbaey, M. and Schokkaert, E. 2012. Inequity in health and health care. In: Barros, P., McGuire, T. and Pauly, M., (Eds.) Handbook of Health Economics, vol. 2, 1003-1092. New York: Elsevier

Fontaine, K.R., Redden, D.T., Wang, C., Westfall, A.O. and Allison, D.B. 2003. Years of life lost due to obesity. Journal of the American Medical Association, 289(2), 187-193.

Kannel, W.B. 1997. Effect of weight on cardiovascular disease. Nutrition, 13(2), 157-158.

Le Grand, J. 1991. Equity and choice. An essay in economics and applied philosophy. London: HarperCollinsAcademic.

McPherson, K., Marsh, T. and Brown, M. 2007. Tackling obesities: future choices modelling future trends in obesity and the impact on health. Project Report Butland.

Mokdad, A.H., Marks, J.S., Stroup, D.F. and Gerberding, J.L. 2004. Actual causes of death in the United States, 2000. Journal of the American Medical Association, 291(10), 1238-1245. 
Morreim, E.H. 2000. Sticks and carrots and baseball bats: economic and other incentives to modify health behavior. In: Callahan, D. (eds.) Promoting healthy behavior. Washington DC: Georgetown University Press, 56-75.

Quesenberry, C.P., Caan, B. and Jacobson, A. 1998. Obesity, health services use, and health care costs among members of a health maintenance organization. Archives of Internal Medicine, 158(5), 466-472.

Rawls, J. 1971. A theory of justice. Cambridge, Mass.: Harvard University Press.

Roemer, J. 1998. Equality of opportunity. Cambridge, Mass.: Harvard University Press.

Schmidt, H. 2007. Personal responsibility for health - Developments under the German healthcare reform 2007. European Journal of Health Law, 14, 241-250.

Schokkaert, E. and Devooght, K. 2003. Responsibility-sensitive fair compensation in different cultures. Social Choice and Welfare, 21, 207-242.

Sen, A. 1999. Development as freedom. New York: Knopf.

Ubel, P., Baron, J. and Asch, D. 1999. Social responsibility, personal responsibility, and prognosis in public judgments about transplant allocation. Bioethics, 13, 57-68.

Underwood, M.J. and Bailey, J.S. 1993. Coronary bypass surgery should not be offered to smokers. British Medical Journal, 306, 1047-1050.

Visscher, T. and Seidell, J. 2001. The public health impact of obesity. Annual Review of Public Health, 22, 355-375.

World Cancer Research Fund 1997. Food, Nutrition and the Prevention of Cancer: A Global Perspective. Washington DC: American Institute for Cancer Research. 